\title{
Incidência das Barreiras Não Tarifárias no Contexto do Acordo UE-Mercosul
}

Impact of non-tariff barriers in the context of the EU-

Mercosur Agreement

\section{Impacto de las barreras no arancelarias en el contexto del Acuerdo UE-Mercosur}

Michelle Márcia Viana Martins'

Heloísa Lee Burnquist²

DOI: 10.5752/P.2317-773X.2021v9.n1.p51

Recebido em: 9 de novembro de 2019

Aprovado em: 25 de maio de 2020

1. Economista e mestre em economia Doutoranda em economia aplicada na ESALQ/USP. Piracicaba, Brasil. Orcid: 0000-0002-0790-5625

2. Agrônoma e PhD em Agricultural Economic. Professora titular do Departamento de Economia, Administração e Sociologia na ESALQ/USP. Piracicaba, Brasil. Orcid: 0000-0001-9856-0118

\section{Resumo}

O avanço das negociações do Acordo UE-Mercosul colocou em pauta a configuração da política comercial ao propor a redução tarifária de uma série de produtos, principalmente os bens agroalimentares. Todavia, desde a criação da OMC a incidência de tarifas vem sido substituída por barreiras não-tarifárias, das quais destacam-se as medidas sanitárias e fitossanitárias (SPS) e técnicas (TBT). Esse estudo teve o objetivo de fazer um levantamento das informações sobre as exigências SPS e TBT entre os blocos investigados, através da avaliação de inventários. A maior parte das emissões tiveram o intuito de promover a segurança alimentar, ao reduzir o risco de contaminação via comércio de commodities agrícolas. Os setores cárneo e frutícola foram os mais afetados pelas regulamentações. Além disso, observou-se que a União Europeia emitiu maior volume de notificações com finalidade de proteger o mercado interno da concorrência externa, indicando prática de protecionismo disfarçado. Para futuros avanços nas negociações, é necessário que as partes alcancem definições comuns com vistas a promover as mercadorias que favorecem ambos.

Palavras-chave: Barreiras comerciais. Acordo comercial. Medidas sanitárias e fitossanitárias. Medidas técnicas. Comércio internacional.

\section{RESUMEN}

El progreso de las negociaciones sobre el Acuerdo UE-Mercosur puso la configuración de la política comercial en la agenda al proponer una reducción arancelaria para un conjunto de productos, principalmente los agroalimentarios. Sin embargo, desde la creación de la OMC, la incidencia de los aranceles ha sido reemplazada por barreras no arancelarias, como las medidas sanitarias y fitosanitarias (SPS) y técnicas (TBT). Esta investigación tuvo como objetivo analizar la información sobre los requisitos de SPS y TBT entre los bloques investigados a través de la evaluación de inventarios. La mayoría de las emisiones estaban des- 
tinadas a promover la seguridad alimentaria al reducir el riesgo de contaminación a través del comercio de productos agrícolas. Los sectores de carne y fruta fueron los más afectados por las regulaciones. Además, se observó que la Unión Europea emitió más notificaciones destinadas a proteger el mercado interno de la competencia externa, lo que indica un proteccionismo encubierto. Para seguir avanzando en las negociaciones, las partes deben llegar a definiciones comunes para promover bienes que favorezcan a ambos.

Palabras-clave: Barreras comerciales. Acuerdo comercial. Medidas sanitarias y fitosanitarias. Medidas técnicas. Comercio internacional.

\section{ABSTRACT}

The progress of the negotiations on the EU-Mercosur Agreement put the trade policy configuration on the agenda by proposing a tariff reduction for a number of products, mainly agrifood goods. However, since the creation of the WTO, the incidence of tariffs has been replaced by non-tariff barriers, such as sanitary and phytosanitary (SPS) and technical (TBT) measures. This study aimed to survey the information on SPS and TBT requirements among the blocks investigated through the assessment of inventories. Most emissions were intended to promote food security by reducing the risk of contamination via trade in agricultural commodities. The meat and fruit sectors were most affected by the regulations. In addition, it was noted that the European Union issued more notifications aimed at protecting the internal market from external competition, indicating undercover protectionism. For further progress in the negotiations, the parties need to reach common definitions to promote goods that favor both.

Keywords: Trade barriers. Trade agreement. Sanitary and phytosanitary measures. Technical measures. International trade.

Introdução

Em 2019, foi concluída parte comercial do tratado de livre comércio entre os países membros dos blocos Mercado Comum do Sul (Mercosul) e União Europeia (UE), cujo objetivo é constituir a maior área de livre comércio do mundo, através da liberalização comercial. Ainda que não tenha sido ratificado pelos congressos nacionais dos países do Mercosul e pelo Parlamento Europeu, o processo de negociação iniciou-se em 1995, com a assinatura do Acordo-Quadro de Cooperação Inter-regional Mercosul-União Europeia e prevê os interesses dos agentes envolvidos pautados, basicamente, na eliminação de barreiras protecionistas.

No início do diálogo sobre uma possível relação comercial, a UE buscava expandir seus mercados e aumentar a competitividade dos produtos em um contexto em que os Estados Unidos emergia como superpotência no pós-Guerra Fria. A consolidação de um acordo com o Mercosul reforçaria a posição das empresas europeias no Cone Sul e possibilitaria a importação de matérias-primas a menores custos. Já o Mercosul buscava expandir o comércio de commodities agrícolas para promover o desenvolvimento econômico via aumento das exportações, nesse contexto a UE representava um mercado potencial (MARIANO et al., 2019). No entanto, o pacto comercial pelas perspectivas dos Estados, não atendiam aos interesses bilaterais, visto que as ofertas de acesso aos bens eram insatisfatórias (SILVA-REGO e FIGUEIRA, 2018). 
Embora as negociações não demonstrassem progresso, as economias europeias e do bloco sul-americano são signatárias à Organização Mundial do Comércio (OMC) desde sua criação, em 1995. Desde então, estão de acordo com os seus propósitos, sendo a redução gradativa da emissão de tarifas o principal deles. A política tarifária é caracterizada como obstáculo comercial, impactando diretamente os fluxos de comércio, de forma a reduzi-los (PIANI e KUME, 2000; AZEVEDO et al., 2006). Segundo Martins et al. (2018), o cumprimento dos objetivos da OMC tem reduzido a importância relativa das tarifas. Todavia, emergiram outros desafios referentes às transações no comércio exterior, as chamadas Barreiras Não Tarifárias (BNT’s).

Esses novos impasses comerciais tratam de políticas que não fazem o uso de tarifas, porém, podem apresentar efeitos econômicos semelhantes, alterando os preços e os volumes comercializados. As BNT's são caracterizadas pelo seu efeito ambíguo, pois ao mesmo tempo em que são utilizadas para reduzir as assimetrias de informação, minimizar os riscos no consumo, melhorar a sustentabilidade dos ecossistemas e influenciar a decisão de importação ou exportação. Não obstante, podem também ser caracterizadas como medidas de protecionismo disfarçado, com o intuito de proteger os mercados internos da concorrência internacional.

Entre as BNT’s destacam-se as Medidas Sanitárias e Fitossanitárias (Sanitary and Phitosanitary Measures - SPS) e Técnicas (Technical Barriers to Trade - TBT). Os Acordos SPS e TBT foram instituídos pela OMC para promover o princípio da transparência no mercado internacional. Mais especificamente, é cabível às medidas SPS proteger e resguardar a saúde humana, animal e vegetal, garantindo acesso a produtos e serviços seguros via comércio exterior e, às medidas TBT cabem promover normas e regulamentos técnicos para assegurar os objetivos citados sem prejudicar o comércio (SANTOS e SILVA, 2013).

As exigências são baseadas em padrões científicos próprios de cada nação, com a tendência de os requisitos definidos por economias mais desenvolvidas serem mais rigorosos quando comparados aos padrões determinados pelos países de menor renda (OTSUKI et al.,2001; HENSON e JAFFEE, 2008). Assim, se por um lado os Acordos SPS e TBT propõem-se em padronizar e desenvolver a segurança alimentar, garantido aos países acesso a produtos dentro dos padrões técnicos e sem riscos de contaminação; por outro, podem incorrer em exigências tão rigorosas que inviabilizam a adequação por parte dos produtores, que optam por sair do mercado, causando distorções no comércio (MARTINS e SILVA; 2016).

O Acordo UE-Mercosul estabelece o compromisso de boas práticas regulatórias entre os países envolvidos, buscando alinhar os padrões nacionais com os internacionais existentes. Sobre as medidas SPS, os blocos negociaram obrigações que promoverão previsibilidade e transparência no comércio de produtos do agronegócio. Por exemplo, o estabelecimento de procedimentos de inspeção que reconhecem as boas práticas sanitárias e fitossanitárias dos países. Em relação aos regulamentos técnicos, foi preservado o modelo de certificação europeu e dialogado sobre a redução da complexidade dos procedimentos exigidos pelas economias latinas. Segundo as empresas europeias, os processos instituídos pelos membros do 
Mercosul, para comprovar adequação dos produtos europeus às normas técnicas, são desnecessários, o que condiz com práticas de concorrências desleais para limitar o acesso da UE.

O bloco europeu aposta que o acordo comercial com o Mercosul elimine obstáculos excessivos e discriminatórios às exportações europeias. No entanto, pontua-se que a UE exige que os países do Cone Sul sejam coerentes com seus altos padrões de exigências. As regras europeias não serão alteradas e o acordo não afetará a legislação já estabelecida, visto que as normas se aplicam a todos os produtos vendidos dentro do bloco, produzidos internamente ou importados (EC, 2019).

Neste sentido, visto que os países europeus apresentam padrões mais exigentes e que as economias membros do Mercosul adotam posturas discriminatórias na aplicação de BNT's, esse estudo busca fazer um levantamento dos requisitos existentes nas matérias reguladas e que podem apresentar efeitos no comércio após a ratificação do acordo. Especificamente, pretende-se realizar uma abordagem metodológica de inventário para comparar os regulamentos sanitários e técnicos emitidos pelos países membros dos blocos, em um o horizonte temporal de vinte e três anos, iniciado em 1995, da criação da OMC, até o período mais recente, 2018.

A análise será pautada em produtos agroalimentares, dado que as economias do Mercosul são essencialmente agrárias-exportadoras e as medidas sanitárias e fitossanitárias recaem, majoritariamente, sobre esse tipo de produto (HOEKMAN e NICITA, 2011). Além disso, o acordo prevê isenção de tarifas alfandegárias em $91 \%$ dos produtos oriundos do agronegócio, enviados da UE para o Mercosul e em 92\% das commodities exportadas pelas economias latinas para as europeias, entre 2019 a 2029 (EC, 2019).

O longo e lento processo de negociação demonstra que embora as economias estivessem inclinadas em ratificar o acordo, era necessário superar uma série de impasses que impediam a convergência dos interesses. Mesmo depois de ser anunciada a conclusão da parte comercial do Acordo de Associação Mercosul-UE, é despertado o questionamento: quais interesses comerciais podem ser contrariados?

Os resultados obtidos contribuem para a literatura já que não há trabalhos com o mesmo enfoque. A partir destes, é possível investigar sobre evolução da emissão das medidas em análise, permitindo fazer inferências sobre os produtos mais afetados e possíveis tendências. Assim, busca-se incitar o debate sobre os diferentes níveis de rigor em relação as exigências que afetam o comércio, cabendo aos países interessados dialogarem sobre suas políticas regulatórias com vistas a atenuar as divergências comerciais.

\section{As medidas SPS e TBT no contexto das transações comerciais}

De acordo com Vaillant e Vaillant (2014), a falta de transparência das políticas tarifárias entre UE e Mercosul dificultaram as negociações entre os blocos entre 2000 e 2013. Primeiramente, os europeus buscavam ampliar o mercado de bens manufaturados e serviços. Já o Mercosul, desejava uma agenda curta, com vistas a aumentar apenas o acesso aos 
produtos agrícolas. Mesmo que Paraguai e Uruguai estivessem dispostos a fazer abertura comercial via redução das tarifas, Argentina e Brasil apresentavam-se claramente protecionistas sobre a indústria manufatureira, alegando que a assinatura ao acordo ameaçaria os ajustes produtivos nacionais no setor. Por outro lado, a liberalização tarifária oferecida pela UE não era suficiente para promover as commodities agrícolas do Cone sul. A falta de consenso entre as políticas comerciais confere opacidade às negociações de acesso aos mercados, sendo necessário um maior esforço técnico para obtenção de ofertas equilibradas.

Outro fator que dificultou a elaboração de um acordo é o fato de o Mercosul não apresentar uma zona sanitária única, como ocorre na UE. As prioridades comerciais entre os países latinos diferenciavam-se entre si de acordo com seus produtos de interesse. Porém, houve disposição por parte dos membros em negociar os aspectos sanitários que afetariam o intercâmbio de produtos agroalimentares com a UE. Em 2002, na reunião de Madri, os Estados partes do Mercosul e os Chefes de Estado e de Governo europeus concordaram em abrir negociações sobre as medidas SPS, reiterando que o Acordo resultante seria integrado em um compromisso único para o futuro Acordo Birregional de Associação (BLASETTI, 2004).

No entanto, as exigências sanitárias, fitossanitárias e técnicas que regem a importação de produtos agroalimentares no Mercosul e UE devem ser normatizados juntos à OMC. Quando um país vê a necessidade de regulamentar algum produto, com o objetivo de resguardar-se contra os riscos associados ao consumo de produtos provenientes de outros países, deve emitir notificações ao país exportador para informar alteração em seus regulamentos internos (BRITO et al., 2011). No entanto, mesmo que a legislação nacional seja consistente com a OMC, que busca garantir que as regulamentações não impliquem em restrições injustificadas ao comércio, existem diferenças quanto à interpretação e implementação efetivas das obrigações.

Neste sentido, para reduzir a assimetria de informação entre os agentes comerciais, a OMC estabelece centros de informações ou os chamados pontos focais, que fornecem esclarecimentos sobre os regulamentos enviados pelos países aos demais membros da Organização. Além disso, contam com instituições que criam padrões internacionais que servem de referência aos países que sustentam cientificamente as questões relativas aos Acordo SPS e TBT, sendo eles, o International Organization on Standards (ISO), International Electrotechnical Organizations (IEO), International Telecommunications Union (ITU), Codex Alimentarius, a Oficina Internacional de Epizootias (OIE) e a International Plant Protection Convention, IPPC (MENDONÇA et al., 2017). Em muitos casos, os padrões europeus incorporam requisitos que não são contemplados nos regulamentos internacionais acima mencionados ou impõe padrões mais exigentes que os internacionais.

A este fato, podem emergir conflitos potenciais entre as partes envolvidas em uma negociação bilateral. Como exemplo, vale mencionar a proposta na mudança da definição de "carne fresca" pela UE, que passa a ser denominada como "carne que não tenha sido reforçada a qualquer momento, cujo processo de resfriamento seja mantido entre as tempe- 
raturas $-2^{\circ}$ e $4^{\circ} C^{\prime}$. Essa alteração torna a definição da carne mais rigorosa do que as normas internacionais, sendo essa exigência caracterizada como uma discriminação dos produtos importados em favor dos produtores europeus, pois apenas esses teriam condições de comercializar esse tipo de carne (EUR-Lex, 2009).

Em outro momento, Oliveira (2005) ressaltou que os requisitos de segurança alimentar, emitidos pela UE no período de 1995 a 2004 para o setor de frutas, apresentou tendências mais rigorosas relacionadas ao Limite Máximo de Resíduos (LMR) do que as recomendadas pelo Codex. O resultado sugere que o alto rigor europeu imposto aos regulamentos sanitários, demanda alto empenho dos países importadores para atingirem seus mercados. Na ausência de justificativas científicas, os altos padrões da UE podem ser entendidos, pelas economias em desenvolvimento, como barreiras protecionistas ao comércio, visto que esses países não dispõem de condições técnicas para comprovar que seus produtos cumprem aos requisitos.

Kox et al. (2007) e Aussilloux et al. (2011) reforçam que as barreiras não tarifárias são responsáveis por fragmentar o comércio mundial e a eliminação desses obstáculos pelos países europeus é um cenário irrealistas, principalmente no setor agroalimentar. Segundo Guimarães (2012), as BNT's atingem até $50 \%$ dos fluxos de produtos advindos do agronegócio. Esse argumento encontra respaldo nos trabalhos de Otsuki et al. (2001), Arita et al. (2015), e Murina e Nicita (2017).

Otsuki et al. (2001) quantificaram o impacto de um novo padrão harmonizado de aflatoxinas estabelecido pela UE, sobre as exportações africanas de cereais, frutas secas e castanhas. Os resultados apontaram que o efeito das mudanças em diferentes níveis de proteção da UE, em contraste com os sugeridos pelos padrões internacionais, reduz o volume exportado da África para a Europa. O mesmo impacto negativo sobre o comércio foi encontrado por Arita et al. (2015), ao investigarem a incidência de medidas SPS e TBT sobre o comércio de commodities alimentares entre EU e Estados Unidos. Foi concluído que os requisitos impostos pelo bloco europeu pelos produtos americanos - aves, suínos e milho, têm efeitos mais impeditivos ao comércio do que as próprias tarifas, sendo equivalentes tarifários ad valorem em proporções de 102, 81 e 79\%, respectivamente.

Murina e Nicita (2017) trouxeram ao debate as distorções comerciais causadas pelas medidas regulatórias impostas pela UE sobre os países de baixa renda. Foi constatado que os produtos agrícolas que ingressam no mercado europeu precisam cumprir um número substancial de medidas SPS, sendo este maior de acordo com a importância do produto na pauta comercial do bloco. Além disso, quanto menos desenvolvida uma economia, maiores são os encargos relacionados às medidas SPS.

Esses trabalhos reforçam que o acesso à UE tem sido recorrentemente determinado pela capacidade de cumprir o marco regulatório. Os países de menor renda devem superar esses impasses para aumentarem sua parcela comercial nesse mercado. No âmbito do Acordo UE-Mercosul, essa questão é evidente. Primeiro, pela a discrepância do nível de renda entre os países envolvidos. Segundo, as rigorosas normas da UE não 
são negociáveis. Como em todos os acordos comerciais da UE, o acordo com o Mercosul não alterará os padrões europeus, incluindo os de alimentos, produtos agrícolas e de pesca

No entanto, estudos empíricos demonstram que os regulamentos SPS e TBT podem apresentar efeito positivo no comércio em termos de bem-estar. O benefício pelo ganho de utilidade do consumidor ao adquirir um produto de maior qualidade, supera os custos de conformidade dos produtores. Por exemplo, Fasserella et al. (2011) analisaram as exportações brasileiras de aves para e UE e outros parceiros e verificaram que, conforme as políticas governamentais são conduzidas para estimular o fornecimento de informações sobre o produto avícola nacional, maior tende a ser o fluxo de comércio desse produto. Isso é particularmente interessante, pois com essa prática, o Brasil informa aos seus parceiros comerciais suas condições de higiene e outros aspectos sanitários e técnicos.

Chen et al. (2008) corroboraram com um estudo que analisou uma ampla gama de requisitos TBT para os países desenvolvidos, quais sejam, regulamentos de qualidade, rotulagem, procedimentos de teste e certificação. Foi constatado que quanto maior os padrões adotados pelas empresas exportadoras, maiores são as suas possibilidades de exportarem pelo menos um produto. Os autores ressaltam ainda que, embora a conformidade com as exigências internacionais incorra em altos riscos, seu efeito sobre a disposição do consumidor em pagar por esse bem é diferente. Isso posto, o aumento da informação reduz a incerteza dos consumidores sobre a qualidade de um produto.

Fasserella et al. (2011) e Chen et al. (2008) sustentam que os padrões sanitários e técnicos podem servir como impulso para o crescimento das exportações no longo prazo, sobretudo no setor agrícola e alimentar. $\mathrm{O}$ que pode ser visto, também, em Swinnen (2016), que enfatizou a importância de um país em regulamentar seus produtos e processos para estimular a demanda a um país que pode compensar os custos adicionais introduzidos pelos requisitos. Neste sentido, o acordo entre UE e Mercosul exigirá que os países atuem conjuntamente nos órgãos internacionais na adequação das regulamentações.

Neste contexto analítico, os trabalhos que envolvem a abordagem de inventário contribuem com os registros das normas, regulamentos e notificações à OMC. Beghin e Bureau (2001) apresentaram uma série de estudos que categorizam as medidas SPS e TBT, através da abordagem de inventário. Por exemplo, Swann et al. (1996) contabilizaram as normas nacionais e internacionais reconhecidas pelo Reino Unido e Espanha. Através da análise econométrica foi possível estimar o impacto dessas medidas.

A contagem e descrição dos regulamentos podem ser empregadas para fins diversos. Moenius (2004) coletou informações sobre as possíveis medidas restritivas para observar tendências no setor industrial. Fontagné et al (2005) fizeram um levantamento de dados por inventário para aplicarem em um índice que permite fazer inferências sobre as regulações ambientais e seu potencial efeito comercial. Para o setor de alimentos, Henson et al. (2001) compararam os regimes regulatórios de qualida- 
3. As notificações da União Europeia foram analisadas considerando as emissões do bloco e não dos países membros individualmente. Para o Mercosul, considerou-se o somatório dos informes emitidos pela Argentina, Brasil, Paraguai e Uruguai.

4. HSO2 Carnes e miudezas, comestíveis; HSO3 Peixes e crustáceos, moluscos e os outros invertebrados aquáticos HSO4 Leite e laticínios; ovos de aves: mel natural; produtos comestíveis de origem animal, não especificados nem compreendidos em outros Capítulos: HS05 Outros produtos de origem animal, não especificados nem compreendidos em outros Capítulos; HSO6 Plantas vivas e produtos de floricultura; $\mathrm{HSO}$ Produtos hortícolas, plantas, raízes e tubérculos, comestíveis; HS08 Frutas; cascas de cítricos e de melões; HSOS Café, chá, mate e especiarias; HS10 Cerais; HS11 Produtos da indústria de moagem; malte; amidos e féculas inulina; glúten de trigo; HS12 Sementes e frutos oleaginosos; grãos, sementes e frutos diversos; plantas industriais ou medicinais; palhas e forragens; HS13 Gomas, resinas e outros sucos e extratos vegetais; HS14 Matérias para entrançar e outros produtos de origem vegetal, não especificados nem compreendidos em outros Capítulos; HS15 Gorduras e óleos animais ou vegetais; produtos da sua dissociação; gorduras alimentares elaboradas; ceras de origem animal ou vegetal; HS16 Preparações de carne, de peixes ou de crustáceos, de moluscos ou de outros invertebrados aquáticos; HS17 Açúcares e produtos de confeitaria; HS18 Cacau e suas preparações; HS19 Preparações à base de cereais, farinhas, amidos, féculas ou de leite; produtos de pastelaria; HS2O Preparações de produtos hortícolas, de frutas ou de outras partes de plantas: HS21 Preparações alimentícias diversas HS22 Bebidas, líquidos alcoólicos e vinagres; HS23 Resíduos e desperdícios das indústrias alimentares. de e segurança alimentar entre Estados Unidos e a Comunidade Europeia para identificar as diferenças entre os respectivos sistemas.

Para Beghin e Bureau (2001) o método de inventário pode propiciar informações úteis quanto à caracterização do problema das barreiras não tarifárias para setores ou países específicos. Além de permitir a investigação sobre a extensão do comércio afetado.

$$
\text { Metodologia }
$$

Para analisar a forma como vem ocorrendo a definição e adoção das normas SPS e TBT relacionadas ao comércio de produtos agroalimentares, foi empregada a análise de inventário, que permite levantar informações sobre as notificações emitidas pelos blocos UE e Mercosul ${ }^{3}$ e pelos demais países da OMC, para o período entre 2008 a 2018. O procedimento metodológico é conduzido de forma a identificar, organizar e interpretar padrões nas informações. Para catalogar os regulamentos (identificação e descrição), é tomado como base o conjunto de relatórios que listam as várias medidas nas áreas técnica, sanitária e fitossanitária, disponíveis pela OMC (WTO; 2019).

Pela análise dos inventários, buscou-se identificar os produtos afetados, objetivos das medidas, entre outros fatores que puderam ser isolados e analisados por bloco/país e ao longo do tempo. Foi realizado o cruzamento entre as categorias, como por exemplo, análise dos casos notificados por setor afetado e por objetivo da medida. Procurou-se, também, relacionar as notificações emitidas pelo Mercosul e UE com aquelas emitidas para o mundo como um todo, estabelecendo, quando houvesse, semelhanças nos objetivos e comportamento das emissões.

A notificação é um instrumento de transparência previsto pela OMC, cujos países-membros da OMC submetem ao conhecimento e avaliação uns dos outros. Esta análise pode sinalizar tendências relevantes na normalização internacional, relacionadas a novas exigências.

Os informes SPS e TBT podem ser de dois tipos: regulares e emergenciais. As regulares possuem natureza informativa, a fim de esclarecer aos países notificados sobre as exigências relativas às importações, podendo receber comentários e/ou contestações. As emergenciais estão, geralmente, ligadas a alguma situação crítica de perigo eminente, tal como uma doença contagiosa, por exemplo (HERINGER e SILVA, 2014). Esse estudo em pautado apenas nas notificações regulares.

A análise sobre os produtos segue o Sistema Harmonizado de dois dígitos (HS-02), que consiste no método internacional de classificação de mercadorias. Os bens agroalimentares estão compreendidos entre as classificações HS02 a HS234, com exceção dos produtos HS05, HS06 e HS14, que não são adequados para consumo.

Resultados e Discussões

A evolução das notificações emitidas entre 1995 e 2018 são apresentadas na Figura 1. Observa-se a tendência crescentes das emissões ao longo dos anos, demonstrando o aumento da importância relativa das BNT's 
no decorrer do período. Heringer e Silva (2014) constataram que a intensificação dos regulamentos de caráter sanitário, fitossanitário e técnico, estão diretamente relacionados com a redução das tarifas alfandegárias.

No geral, foram emitidas 41.892 notificações pelos países membros da OMC, das quais 16.135 referem-se ao Acordo SPS (38,52\%) e 25.757 ao Acordo TBT $(61,48 \%)$. Porém, quando considerados apenas os produtos agroalimentares (representados na Figura 1 pelas linhas), o volume de informes SPS superam a quantidade de medidas TBT. Isso se dá pela própria natureza dos produtos investigados, sendo mais susceptíveis às notificações sanitárias e fitossanitárias pelos riscos provenientes de contaminantes, aditivos, toxinas, doenças, pestes e organismos causadores de doenças. Além disso, os produtos analisados são commodities, ou seja, mercadorias pouco diferenciadas. Neste caso, os requisitos TBT restringem-se apenas às características sobre embalagens, pesos, medidas e conformidades.

Figura 1 - Evolução das notificações mundiais SPS e TBT emitidas para todos os produtos (barras) e para o setor agroalimentar (linhas) de 1995 a 2018.

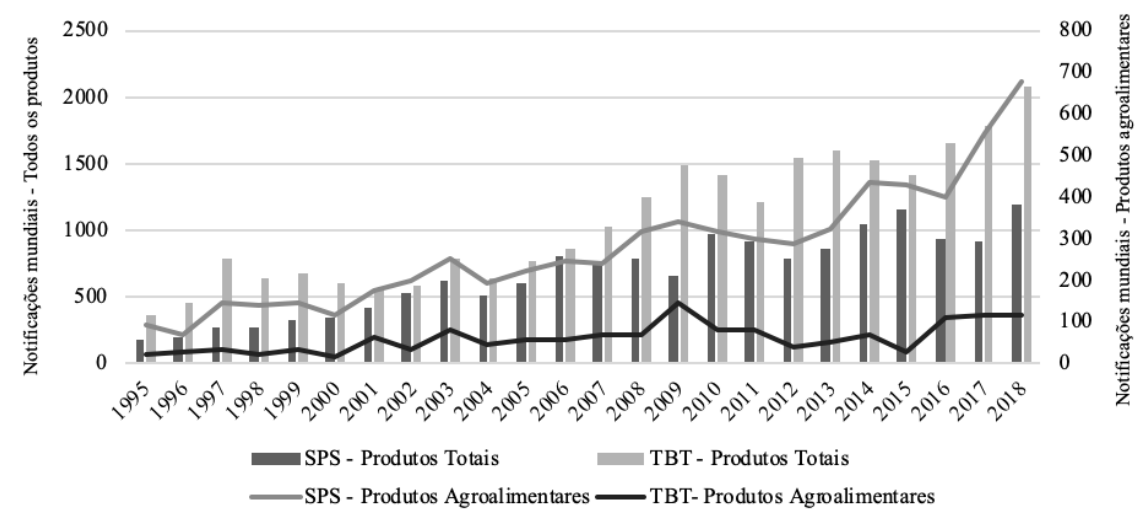

Fonte: Elaboração própria com base nos inventários obtidos pela OMC.

Considerando o ano de 2018, no qual identifica-se o pico de emissões sanitárias e técnicas para os produtos em sua totalidade, há ocorrência de 1.202 e 2.083 notificações, respectivamente. Sendo contabilizadas 677 (SPS) e 147 (TBT) informes enviados para produtos agroalimentares. O Brasil foi o maior emissor SPS, sendo responsável por $12,31 \%$ (148 notificações) do total emitido e $13,00 \%$ (88) direcionadas as mercadorias investigadas. Sobre as notificações técnicas, Quênia apresenta a maior parcela de notificações totais enviadas (172; 8,25\%), seguida da Uganda $(137 ; 6,57)$ e União Europeia (108; 5,18\%). Em relação as commodities, Uganda foi a maior emissora (50;42,02\%), seguida do Brasil $(20 ; 16,81 \%)$.

Sobre os regulamentos emitidos pela UE e Mercosul, o comportamento das notificações SPS é ilustrado na Figura 2. A priori, não é identificado um padrão temporal para as emissões dos países do Cone Sul, diferente dos envios europeus, que apresentaram certa constância ao longo dos anos. Ademais, embora a literatura mostre que a UE tende a ser mais exigente que seus parceiros de menor renda, é observado que os países 
membros do Mercosul emitem notificações sanitárias em maior proporção. No total, o volume emitido pelas economias latinas é $63,70 \%$ maior que o europeu (1.766 emissões contra 641), para os produtos do agronegócio a diferença é de $42,20 \%$ (709 contra 410).

Figura 2 - Evolução das notificações SPS da UE e Mercosul, emitidas para todos os produtos (barras) e para o setor agroalimentar (linhas) de 1995 a 2018.

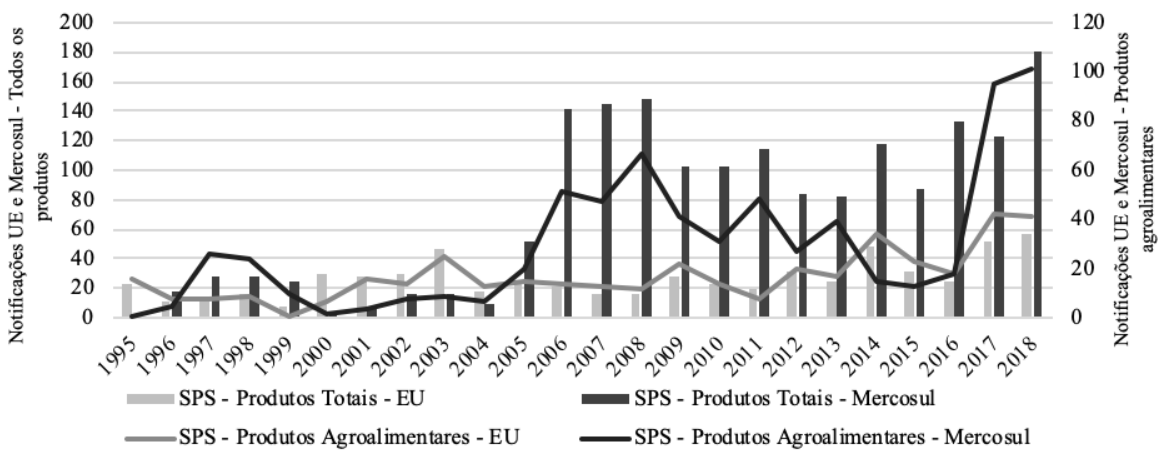

Fonte: Elaboração própria com base nos inventários obtidos pela OMC.

A esse resultado, duas possibilidades podem ser consideradas. Primeiro, indica adequação dos países do Mercosul às normas internacionais, que buscam melhorar a transparência promovendo a harmonização do sistema regulador. Esse argumento faz sentido ao constatar que as emissões sobre produtos agroalimentares, essenciais em sua pauta exportadora, é ainda maior. Essa justificativa encontra respaldo em Henson et al. (2000) e Martins e Silva (2016). A outra possibilidade relaciona-se ao efeito protetor das medidas SPS, visto que a trajetória das emissões não apresenta uma tendência, sendo oscilante entre os anos. $\mathrm{O}$ que demonstra interesse dos países em proteger seus mercados da concorrência externa, em períodos específicos.

As medidas enviadas pelo Mercosul são definidas, majoritariamente, pelo volume brasileiro de emissões. O Brasil é responsável por $84,60 \%$ da quantidade de medidas SPS notificadas, sobre todos os produtos, dentro do bloco. Para os bens em análise, o país detém da parcela de $83,07 \%$ em relação ao demais membros do bloco. Seguido da Argentina (11,49\% e $14,81 \%$, respectivamente), Uruguai $(2,60 \%$ e $1,55 \%)$ e Paraguai (1,30\% e 0,56\%). A Figura 3 aponta para a proporção das notificações sanitárias emitidas pela UE e Mercosul para os produtos agroalimentares. É interessante sublinhar que o Brasil é mais atuante que o bloco europeu na incidência de medidas sanitárias, tendo enviado 589 notificações contra 410. O mesmo desdobramento é válido quando todos os produtos são considerados, a quantidade de notificações emitidas pela UE (641 medidas) equivale a $42,90 \%$ do total brasileiro (1494 medidas). 
Figura 3 - Parcela das notificações SPS enviadas pela UE e Mercosul (esquerda) e pelos países membros do Mercosul (direita) para os produtos agroalimentares.

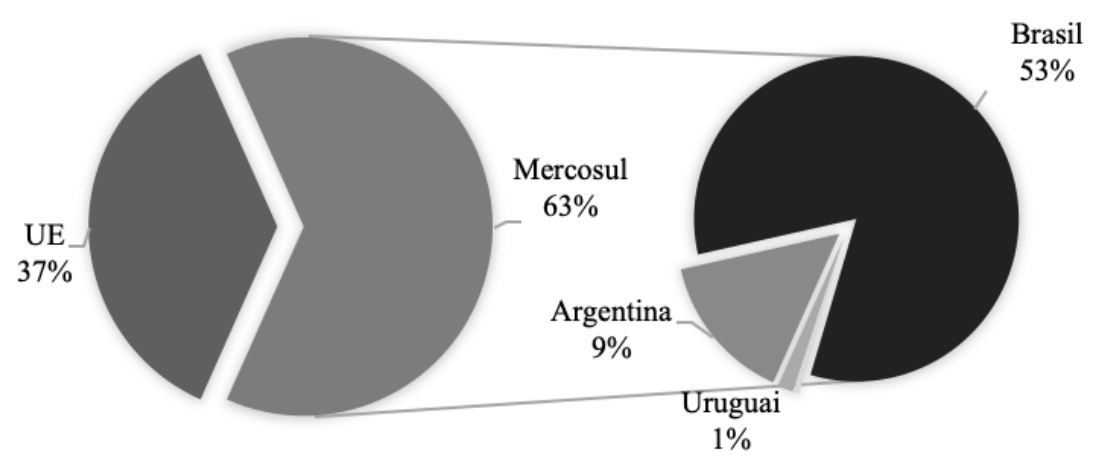

Fonte: Elaboração própria com base nos inventários obtidos pela OMC.

De maneira semelhante, a Figura 4 expõe a trajetória das medidas TBT para os blocos. Assim como observado na Figura 2, as emissões para os produtos agroalimentares (linhas) oscilam entre os anos e não segue o mesmo percurso dos produtos considerados em sua totalidade (barras). A esta última observação, justifica-se pelo fato de que os objetivos das notificações variam de acordo com os setores e as exigências técnicas são mais recorrentes em produtos manufaturados, sendo admitidos uma série de padrões que se diferem-se daqueles incidentes sobre os bens agrícolas. Averiguou-se, também, que a quantidade de notificações técnicas emitidas pelo Mercosul é superior ao volume emitido pelo bloco europeu. Para produtos agroalimentares, a diferença é de $81,62 \%$ (25 contra 136) e no geral, $17,13 \%$ (1.506 contra 1.248).

Figura 4 - Evolução das notificações TBT da UE e Mercosul, emitidas para todos os produtos (barras) e para o setor agroalimentar (linhas) de 1995 a 2018.

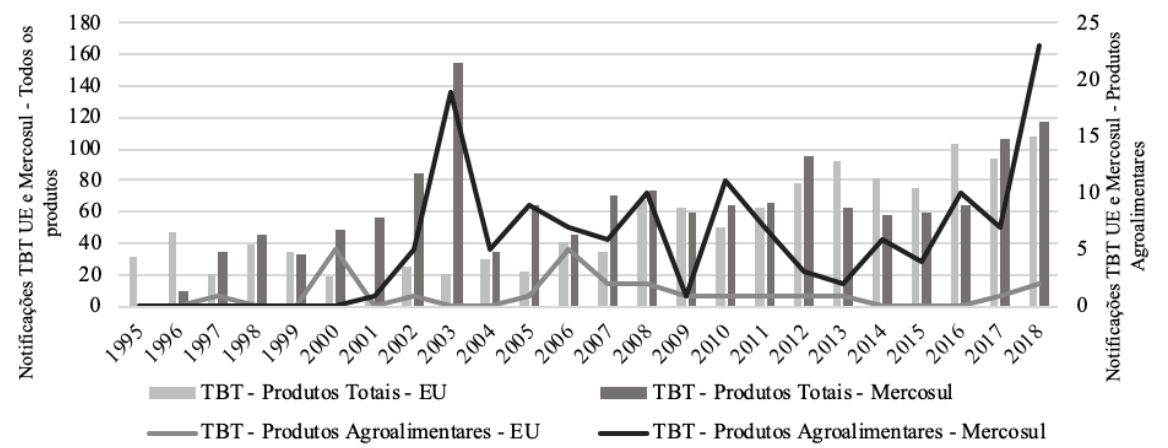

Fonte: Elaboração própria com base nos inventários obtidos pela OMC.

Para as notificações técnicas, o Brasil aparece, mais uma vez, como o maior emissor dentro do Mercosul, representando 64,07\% do volume de medidas TBT enviadas sobre todos os produtos. Para os bens agroalimentares, as emissões do bloco são praticamente provenientes do Brasil, responsável por $94,11 \%$. Já a Argentina é o segundo mais atuante nos envios (27,03\% e 4,41\%, respectivamente), seguido do Uruguai $(7,10 \%$ e $1,47 \%)$ e Paraguai $(1,79 \%$ e 0$)$. Sobre a parcela de emissões pelos blocos, a Figura 5 indica que a UE emitiu apenas $16 \%$, com 25 notificações, já o 
Mercosul, responsável por cerca de $84 \%$ das emissões, enviou 136. Desse valor, Brasil é responsável 79\% das medidas notificadas (128). Ao avaliar todos os produtos, o resultado é distinto. Neste caso, a quantidade de regulamentos emitidos pela UE (1248) é maior que o volume enviado pelo Brasil (965), mas inferior a quantidade do Mercosul (1506).

Figura 5 - Parcela das notificações TBT enviadas pela UE e Mercosul (esquerda) e pelos países membros do Mercosul (direita) para os produtos agroalimentares.

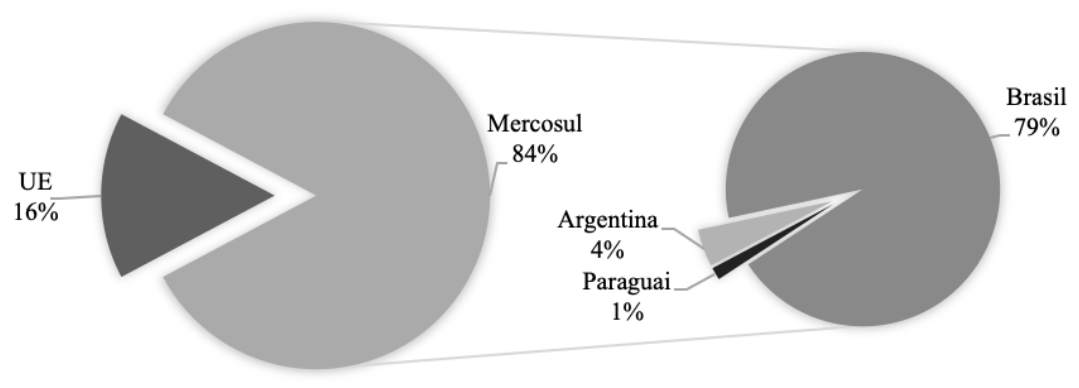

Fonte: Elaboração própria com base nos inventários obtidos pela OMC.

É importante frisar que uma mesma notificação pode referir-se a mais de um produto e direcionado a mais de um país. Por exemplo, a notificação cujo inventário é nomeado por G/SPS /N/UE/153, descreve um regulamento da UE para 19 países e abarca os produtos contidos nos grupos HS07, HS08, HS09, HS11, HS12 e HS20. Neste caso, os resultados obtidos deste ponto em diante devem considerar essa ressalva.

Entre as commodities agrícolas analisadas, os produtos que mais receberam notificações de natureza sanitária, fitossanitária e técnicas são descritos na Tabela 1. Pontua-se que os bens mais notificados pela UE são aqueles do grupo HS02 (Carnes e miudezas comestíveis), sendo, também os que mais recebem envios do resto do mundo. Com 171 notificações europeias, que equivalem a quase $60 \%$ das medidas SPS emitidas. $\mathrm{Na}$ sequência, destacam-se a indústria de Cerais (HS10) e Resíduos das indústrias alimentares (HS23), que recebem 121 e 109 informes, respectivamente. As principais motivações para as emissões do bloco foram promover a "Segurança Alimentar" e "Proteção a Saúde Animal", sendo este os objetivos mais citados.

O maior parte das notificações sanitárias emitidas pelo Mercosul tiveram o intuito de proporcionar a "Segurança Alimentar", "Proteção de Plantas" e "Proteção ao Território", com maior incidência sobre os setores de Frutas; cascas de cítricos e de melões (HS08), com 186 notificações, Sementes e frutos oleaginosos; grãos, sementes e frutos diversos; plantas industriais ou medicinais; palhas e forragens (HS12) com 175 e, Produtos hortícolas, plantas, raízes e tubérculos, comestíveis (HS07), com 130.

Para os regulamentos técnicos, o setor de Bebidas, líquidos alcoólicos e vinagres (HS22) é o mais notificado por ambos os blocos e pelo resto do mundo, sob as justificativas "Prevenção de Práticas Enganosas e Proteção ao Consumidor" e "Requerimento de Qualidade". Além dessas, foi recorrente entre os países latinos o objetivo "Proteção da Saúde ou Segurança Humana”. 
Tabela 1 - Notificações SPS e TBT da UE e Mercosul, para produtos agroalimentar, de 1995 a 2018.

\begin{tabular}{|c|c|c|c|c|c|c|c|c|c|c|c|c|c|c|}
\hline \multirow[b]{3}{*}{ Produtos } & \multicolumn{7}{|l|}{ SPS } & \multicolumn{7}{|l|}{ TBT } \\
\hline & \multirow[b]{2}{*}{ 을 } & \multicolumn{3}{|l|}{ UE } & \multicolumn{3}{|c|}{ Mercosul } & \multirow[b]{2}{*}{ 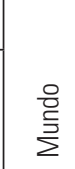 } & \multicolumn{3}{|l|}{ UE } & \multicolumn{3}{|c|}{ Mercosul } \\
\hline & & $\begin{array}{l}\mathrm{N}^{0} \mathrm{de} \\
\text { emis- } \\
\text { sões }\end{array}$ & \begin{tabular}{|l}
$\%$ \\
(Total \\
Mundial)
\end{tabular} & $\begin{array}{l}\% \\
\text { (Total } \\
\text { UE) }\end{array}$ & $\begin{array}{l}\mathrm{N}^{0} \mathrm{de} \\
\text { emis- } \\
\text { sões }\end{array}$ & $\begin{array}{l}\text { \% } \\
\text { (Total } \\
\text { Mundial) }\end{array}$ & $\begin{array}{l}\% \\
\text { (Total } \\
\text { Mercosul)* }\end{array}$ & & $\begin{array}{l}\mathrm{N}^{0} \text { de } \\
\text { emis- } \\
\text { sões }\end{array}$ & $\begin{array}{l}\text { \% } \\
\text { (Total } \\
\text { Mundial) }\end{array}$ & $\begin{array}{l}\% \\
\text { (Total } \\
\text { UE) }{ }^{*}\end{array}$ & $\begin{array}{l}\mathrm{N}^{0} \mathrm{de} \\
\text { emis- } \\
\text { sões }\end{array}$ & $\begin{array}{l}\text { \% } \\
\text { (Total } \\
\text { Mundial) }\end{array}$ & $\begin{array}{l}\% \\
\text { (Total Mer- } \\
\text { cosul) }{ }^{*}\end{array}$ \\
\hline HSO2 & 1486 & 171 & 11,51 & 59,79 & 74 & 4,98 & 10,44 & 99 & 6 & 6,06 & 24,00 & 11 & 11,11 & 8,09 \\
\hline HSO3 & 673 & 36 & 5,35 & 12,59 & 37 & 5,50 & 5,22 & 86 & 0 & 0,00 & 0,00 & 16 & 18,60 & 11,76 \\
\hline HSO4 & 1277 & 48 & 3,76 & 16,78 & 76 & 5,95 & 10,72 & 219 & 2 & 0,91 & 8,00 & 14 & 6,39 & 10,29 \\
\hline HSO7 & 1083 & 44 & 4,06 & 15,38 & 130 & 12,00 & 18,34 & 117 & 1 & 0,85 & 4,00 & 9 & 7,69 & 6,62 \\
\hline HSO8 & 1352 & 47 & 3,48 & 16,43 & 186 & 13,76 & 26,23 & 119 & 3 & 2,52 & 12,00 & 19 & 15,97 & 13,97 \\
\hline HSO9 & 489 & 33 & 6,75 & 11,54 & 29 & 5,93 & 4,09 & 84 & 1 & 1,19 & 4,00 & 7 & 8,33 & 5,15 \\
\hline HS10 & 789 & 121 & 15,34 & 42,31 & 91 & 11,53 & 12,83 & 65 & 2 & 3,08 & 8,00 & 4 & 6,15 & 2,94 \\
\hline HS11 & 148 & 23 & 15,54 & 8,04 & 3 & 2,03 & 0,42 & 75 & 2 & 2,67 & 8,00 & 6 & 8,00 & 4,41 \\
\hline HS12 & 1055 & 37 & 3,51 & 12,94 & 175 & 16,59 & 24,68 & 100 & 2 & 2,00 & 8,00 & 6 & 6,00 & 4,41 \\
\hline HS13 & 52 & 8 & 15,38 & 2,80 & 0 & 0,00 & 0,00 & 26 & 2 & 7,69 & 8,00 & 2 & 7,69 & 1,47 \\
\hline HS15 & 455 & 37 & 8,13 & 12,94 & 9 & 1,98 & 1,27 & 105 & 4 & 3,81 & 16,00 & 10 & 9,52 & 7,35 \\
\hline HS16 & 287 & 29 & 10,10 & 10,14 & 11 & 3,83 & 1,55 & 100 & 2 & 2,00 & 8,00 & 9 & 9,00 & 6,62 \\
\hline HS17 & 106 & 7 & 6,60 & 2,45 & 1 & 0,94 & 0,14 & 91 & 2 & 2,20 & 8,00 & 8 & 8,79 & 5,88 \\
\hline HS18 & 133 & 3 & 2,26 & 1,05 & 9 & 6,77 & 1,27 & 50 & 2 & 4,00 & 8,00 & 5 & 10,00 & 3,68 \\
\hline HS19 & 316 & 25 & 7,91 & 8,74 & 6 & 1,90 & 0,85 & 115 & 3 & 2,61 & 12,00 & 6 & 5,22 & 4,41 \\
\hline HS2O & 267 & 24 & 8,99 & 8,39 & 7 & 2,62 & 0,99 & 180 & 3 & 1,67 & 12,00 & 14 & 7,78 & 10,29 \\
\hline HS21 & 280 & 26 & 9,29 & 9,09 & 7 & 2,50 & 0,99 & 156 & 3 & 1,92 & 12,00 & 11 & 7,05 & 8,09 \\
\hline HS22 & 307 & 10 & 3,26 & 3,50 & 32 & 10,42 & 4,51 & 259 & 11 & 4,25 & 44,00 & 36 & 13,90 & 26,47 \\
\hline HS23 & 543 & 109 & 20,07 & 38,11 & 40 & 7,37 & 5,64 & 51 & 3 & 5,88 & 12,00 & 11 & 21,57 & 8,09 \\
\hline $\begin{array}{l}\text { Total } \\
\text { Produtos } \\
\text { Agroali- } \\
\text { mentares }\end{array}$ & 6615 & 286 & 4,32 & 100,00 & 709 & 10,72 & 100,00 & 1478 & 25 & 1,69 & 100,00 & 136 & 9,20 & 100,00 \\
\hline
\end{tabular}

Fonte: Elaboração própria com base nos inventários obtidos pela OMC.

*Uma mesma notificação pode referir-se a mais de um produto.

Partindo para resultados mais detalhados, buscou-se contabilizar o número de notificações para as commodities agropecuárias de um bloco para o outro, sendo descritos na Tabela 2. A UE enviou 14 notificações ao Mercosul entre os anos de 1995 a 2018 ${ }^{5}$, nenhuma direcionada especificamente a algum países do bloco, mas todas mencionam o Bra-

5. 2001, 1 notificacãa; 2005, 1; 2007, 2; 2009, 2; 2014, 4; 2015, 3 e 2016, 1. sil e uma é referenciada ao Brasil, Argentina e Paraguai. Os produtos mais notificados são aqueles presentes nos grupos HS08, HS11 e HS12, referentes a frutas, produtos da indústria de moagem e sementes, respectivamente, com os objetivos de amparar a "Segurança Alimentar" e "Saúde Animal". 
Tabela 2 - Direcionamento das notificações SPS da UE e Mercosul, para produtos agroalimentares, de 1995 a 2018.

\begin{tabular}{|l|l|l|l|l|l|l|}
\hline SPS & EU $\rightarrow$ EU & EU $\rightarrow$ Mercosul & EU $\rightarrow$ Todos os Parceiros Comerciais & Mercosul $\rightarrow$ EU & Mercosul $\rightarrow$ Mercosul & $\begin{array}{l}\text { Mercosul } \rightarrow \text { Todos os } \\
\text { Parceiros Comerciais }\end{array}$ \\
\hline HS02 & 9 & 6 & 151 & 0 & 17 & 73 \\
\hline HS03 & 6 & 0 & 27 & 0 & 6 & 33 \\
\hline HS04 & 7 & 3 & 34 & 0 & 18 & 73 \\
\hline HS07 & 3 & 8 & 26 & 2 & 13 & 100 \\
\hline HS08 & 3 & 9 & 21 & 0 & 15 & 121 \\
\hline HS09 & 1 & 8 & 18 & 0 & 1 & 24 \\
\hline HS10 & 2 & 0 & 119 & 0 & 6 & 76 \\
\hline HS11 & 1 & 9 & 8 & 0 & 1 & 1 \\
\hline HS12 & 1 & 9 & 22 & 1 & 10 & 111 \\
\hline HS13 & 2 & 0 & 6 & 0 & 0 & 0 \\
\hline HS15 & 3 & 1 & 24 & 0 & 1 & 9 \\
\hline HS16 & 2 & 1 & 23 & 0 & 2 & 9 \\
\hline HS17 & 2 & 0 & 5 & 0 & 0 & 1 \\
\hline HS18 & 0 & 0 & 3 & 0 & 2 & 6 \\
\hline HS19 & 2 & 1 & 21 & 0 & 1 & 5 \\
\hline HS20 & 1 & 7 & 8 & 0 & 1 & 6 \\
\hline HS21 & 3 & 0 & 22 & 0 & 1 & 7 \\
\hline HS22 & 4 & 0 & 6 & 0 & 4 & 32 \\
\hline HS23 & 2 & 1 & 104 & 0 & 10 & 40 \\
\hline Total Produtos & 35 & 14 & 342 & 2 & 37 & 518 \\
\hline ggroalimentares & 35 & & & & \\
\hline
\end{tabular}

Fonte: Elaboração própria com base nos inventários obtidos pela OMC.

Afim de conhecer as principais preocupações europeias em relação aos produtos importados do Mercosul, considerou-se, as principais palavras-chaves empregadas nos informes enviados. "Segurança Alimentar" e "Saúde Humana" foram citadas em 11 notificações; já "Aflatoxinas", "Alimentação Animal", "Bactéria", "Contaminantes", "Micotoxinas", "Salmonela" e "Toxinas" em 8. Entre outras palavras-chaves citadas, tem,-se "Ocratoxina" (7); "Saúde Animal" (5); "Doenças Animais" (4); "Doença de Newcastle" (3); "Zoonoses" (2); "Encefalopatias Espongiformes Transmissíveis" (1); "Aditivos Animais" (1); Gripe Aviária" (1) e "Adoção/Publicação/Entrada em vigor do regulamento" (1). Duas medidas emitidas são pautadas no padrão internacional da Oficina Internacional de Epizootias (OIE), as demais não seguem uma referência.

O Mercosul enviou apenas duas notificações para a UE, com origem na Argentina e Brasil. Ambas têm incidência sobre produtos hortícolas do grupo HS07 e uma considera, ainda, o setor de sementes (HS12). As palavras-chaves identificadas foram "Fitossanidade", "Sementes e "Pragas", sendo coerentes com o objetivo das emissões, que visa a "Proteção de Plantas". O informe argentino foi emitido em 2009, o brasileiro em 2011 e, nenhum deles, é respaldado em algum padrão internacional. 
Outro resultado pertinente faz alusão ao volume de envios que os blocos sobre si, sendo este, maior que os envios entre os blocos. As emissões realizadas pelo Mercosul sobre o próprio bloco somam 37 notificações e, podem estar associadas a correção de ineficiências de mercado, decorrentes de externalidades relacionadas à produção, distribuição e aos riscos associados ao consumo de seus produtos. Neste caso, as medidas sanitárias servem como incentivo aos países membros para o fornecimento do nível de proteção necessário aos produtos comercializados, sinalizando aos parceiros comerciais a preocupação em atingir níveis de qualidade e segurança desejáveis. Reconhece-se, também, que é mais fácil para os países em desenvolvimento negociarem com semelhantes de mesma renda, pois seus requisitos de qualidade tendem a apresentar padrões análogos (MURPHY e SHLEIFER, 1997).

São identificadas 35 notificações europeias sobre os produtos oriundos de países do bloco. É possível que as emissões tenham sido motivadas para corrigir assimetrias de informações e promover a transparência dos produtos consumidos, aliviando as preocupações dos consumidores sobre a qualidade ou segurança do produto. Além disso, de acordo com Frahan e Vancauteren (2006) a harmonização dos padrões sanitários contribui para maiores fluxos de comércio intra-UE ${ }^{6}$.

Na sequência, vale ressaltar que as economias são afetadas pelas medidas não tarifárias quando recebem uma notificação de forma direta, em que o país notificador faz menção à nação ou região afetada; ou indiretamente, se o emissor notifica todos os seus parceiros comerciais. As emissões indiretas são apontadas na Tabela 2 e verifica-se que o bloco europeu emitiu 342 medidas que afetam toda a comunidade comercial, já o Mercosul, 518. Em um primeiro momento, esse resultado pode demonstrar a necessidade dos exportadores em adequaram-se às exigências sanitárias para garantir maior acesso aos mercados. Todavia, a normatização dos países desenvolvidos impõe àqueles em desenvolvimento a adoção de regras e procedimentos vinculados as características próprias dos primeiros. Logo, os regulamentos não refletem, necessariamente, a adequação às condições das economias de alta renda. Para melhor entendimento dos efeitos das medidas, é necessário analisar o comércio bilateral entre os blocos, para cada setor individualmente. O que não cabe aos objetivos propostos.

Não foi possível estabelecer análise detalhada para os regulamentos técnicos, visto que os inventários TBT não apresentam informações sobre o direcionamento das notificações a alguma economia. Dessa forma, subentende-se que todos os parceiros comerciais são afetados.

Na sequência, com o objetivo de verificar em que medida os países da UE e Mercosul têm emitido regulamentos com finalidade de proteger o mercado doméstico, avaliam-se as Preocupações Comerciais Específicas (PCE’s) recebidas pelos mesmos. As PCE's são instrumentos criados pela OMC para evitar que restrições injustificadas sejam levantadas pelos seus países membros. Posto de outra forma, a OMC permite que seus membros questionem sobre as notificações emitidas indevidamente e que possam afetar diretamente o fluxo comercial. Esse informe é levado ao conhecimento do Comitê de Soluções de Controvérsias, promovendo o

6. Comércio entre os países da UE. 
diálogo entre os países emissor e afetado na tentativa de solucionar os inquéritos. As PCE's levantadas contra a UE e Mercosul, estão dispostas na Tabela 3.

Tabela 3 - PCE's recebidas pelos blocos EU e Mercosul, entre 1995 a 2018.

\begin{tabular}{|c|c|c|c|c|c|c|c|c|}
\hline \multicolumn{9}{|l|}{ SPS } \\
\hline \multirow{3}{*}{$\frac{\text { Origem }}{\text { Destino }}$} & \multicolumn{4}{|c|}{ Todos os produtos } & \multicolumn{4}{|c|}{ Produtos Agroalimentares } \\
\hline & \multicolumn{2}{|c|}{ Todos os parceiros } & \multirow{2}{*}{$\begin{array}{l}\text { Mercosul } \\
\text { UE }\end{array}$} & \multirow{2}{*}{$\frac{\text { UE }}{\text { Mercosul }}$} & \multicolumn{2}{|c|}{ Todos os parceiros } & \multirow{2}{*}{$\begin{array}{l}\text { Mercosul } \\
\text { UE }\end{array}$} & \multirow{2}{*}{$\frac{\text { UE }}{\text { Mercosul }}$} \\
\hline & UE & Mercosul & & & UE & Mercosul & & \\
\hline & 92 & 23 & 20 & 10 & 49 & 16 & 11 & 6 \\
\hline \multicolumn{9}{|l|}{ TBT } \\
\hline & 280 & 35 & 38 & 30 & 4 & 3 & 3 & 3 \\
\hline
\end{tabular}

Fonte: Elaboração própria com base nos inventários obtidos pela OMC.

O número de PCE's recebidos pela UE é superior ao volume verificado pelo Mercosul, tanto para os regulamentos sanitários e fitossanitários quanto para as regulamentações técnicas. No geral, cerca de 14,35\% das notificações europeias receberam contestações contra apenas 1,30\% das emissões do bloco latino. Para os produtos agroalimentares, essa proporção é de $11,95 \%$ para a UE e 2,57\% para o Mercosul. Das 49 reclamações destinadas ao bloco europeu para os produtos agropecuários, 11 foram mantidas pelo Mercosul (22,45\%), enquanto das 16 PCE's recebidas pelos países da América do Sul, 6 foram levantadas pela UE (37,5\%). Análise análoga é estendida para as notificações técnicas, ressaltando que 100\% das PCE's recebidas pelo Mercosul para os produtos alimentares foram provenientes da UE.

A análise das PCE’s sugere que as medidas não tarifárias podem atuar como barreiras ao comércio, por isso são contestadas. Nesta perspectiva, os países europeus são relativamente mais protecionistas que as economias do bloco latino. Esse resultado reforça a necessidade de um acompanhamento constante das notificações emitidas pelos parceiros comerciais.

Por fim, para que um acordo seja estabelecido entre os blocos, é necessário que as regras comerciais de ambos promovam transparência e credibilidade, de tal forma que não sejam utilizadas com o objetivo de promover o protecionismo e distorcer o comércio.

Considerações Finais

Desde 1995, a fraca liberalização tarifária oferecida pela UE e Mercosul não foi suficiente para pactuar um acordo entre os blocos. No entanto, com o avanço das negociações, em 2019, foi concluída parte comercial do Acordo Associação Mercosul-UE. Neste domínio, o setor agroalimentar será um dos mais beneficiados, visto que a UE é a maior importadora de produtos agrícolas no mundo e o Mercosul o segundo maior fornecedor. Propostas ambiciosas foram promovidas ao setor de bens agroalimentares, cuja redução tarifária ocorrerá em grande parte dos produtos comercializados. 
Para promover a transparência nas trocas comerciais, os países demonstram suas preocupações e exigências através de medidas não tarifárias, com destaque às medidas sanitárias e fitossanitárias (SPS) e técnicas (TBT). Partindo da abordagem metodológica de inventário, foram avaliadas as notificações emitidas entre os blocos. O Mercosul sobressaiu como o bloco mais atuante na emissão de informes, sobretudo em matéria de segurança alimentar e doença das plantas. Esse resultado revela suas demandas quanto a melhoria na qualidade do produto produzido e vendido no mercado internacional.

Dada a própria natureza das commodities agrícolas, foi esperado que as medidas SPS tivessem sido enviadas em maior proporção em relação às medidas técnicas. O que de fato ocorreu. Os alimentos mais afetados pelas notificações sanitárias das economias latinas estão no grupo de frutas, produtos hortícolas, sementes e grãos. Já a UE, solicitou padrões de qualidade sobre produtos cárneos, cereais e resíduos alimentares. No entanto, as exigências europeias que fazem menção ao Mercosul, apresentam um perfil distinto. Os produtos afetados são as frutas, produtos da indústria de moagem e sementes.

Os resultados esclarecem quais setores devem receber atenção especial por parte dos exportadores. Na possível ratificação do acordo, o fluxo de produtos tenderá a ser maior quanto mais transparentes e harmônicas as regulamentações dos países sobre os processos de produção e distribuição desses bens.

A tendência crescente das notificações SPS e TBT confirma os argumentos de uma substituição crescente das barreiras tarifárias, apontando para a nova configuração das políticas comerciais que regem as transações no mercado internacional. A promoção de um comércio integrado exige esforços por parte de toda a comunidade, para que estejam em conformidade com os padrões de qualidade e segurança. Como consequência, quanto maior a transparência e credibilidade nas trocas, menores serão os riscos associados aos produtos comercializados. No geral, a relação direta entre o tipo de produto exportado e o número de notificações emitidas sugere uma adequação dos países às exigências dos parceiros, mais do que uma intenção deliberada de impor barreiras ao comércio. Isso ficou claro quando o Brasil, por exemplo, foi verificado como o maior exportador de produtos agropecuários dentre o Mercosul, emitindo o maior número de notificações SPS em relação aos demais membros do bloco e aos países da OMC.

Mesmo que as economias analisadas apresentem ideologias políticas, instituições e prioridades econômicas distintas, a averiguação dos pontos díspares pode proporcionar oportunidades de ação conjunta para uma harmonização e/ou reconhecimento de equivalência mútua de suas normas SPS e TBT. Por fim, para futuros avanços sobre o Acordo UE-Mercosul, é necessário que as distintas agendas de negociações das partes alcancem definições comuns. Uma maneira de prover celeridade aos processos seria a redução das questões a serem negociadas, atenuando as ambições esperadas por cada bloco envolvido. Para tanto, seria interessante que fossem negociadas pautas de grande importância para ambos, facilitando a concessão de bens agrícolas pela UE e mercadorias manufaturadas pelo Mercosul. 
Referências

ARITA, S.; MITCHELL, L.; BECKMAN, J. Estimating the effects of selected sanitary and phytosanitary measures and technical barriers to trade on US-EU agricultural trade. 2015.

AUSSILLOUX, V.; EMLINGER, C.; FONTAGNÉ, Lionel."What Benefits from Completing the Single Market?". La Lettre du CEPII no 316. Paris, Centre d'Études Prospectives et d'Informations Internationales. 2011.

AZEVEDO, A.F.Z.; PORTUGAL, M.S.; BARCELLOS NETO, P.C.F. Impactos comerciais da área de livre comércio das américas: uma aplicação do modelo gravitacional. Revista de economia contemporânea. Rio de Janeiro. Vol. 10, n. 2 (maio/ago. 2006), p. 237-267, 2006.

BLASETTI, R. Los obstáculos técnicos al comercio de productos agroalimentarios: la negociación UE-MERCOSUR. Revista Aportes para la Integración Latinoamericana, n. 10, p. 1-19, 2004.

BRITO, L. M., SILVA, O. M., ALMEIDA, F. M., GOMES, M. F. M. Análise dos fatores condicionantes da emissão de notificações aos acordos SPS e TBT. Informe GEPEC, v. 15, n. 1, p. 180-195. 2011.

CHEN, M. X.; WILSON, J. S.; OTSUKI, T. Standards and export decisions: Firm-level evidence from developing countries. The Journal of International Trade \& Economic Development, v. 17, $\mathrm{n}$. 4, p. 501-523, 2008.

EC - European Comission. Mercosur. EU-Mercosur trade agreement: the agreement in principle. 2019. Disponível em: <https://trade.ec.europa.eu/doclib/docs/2019/june/tradoc_157964. pdf $>$. Acesso em out. 2019.

EUR-Lex - Access to European Union law. Council Regulation (EC) No 1047/2009 of 19 October 2009 amending Regulatin (EC) No 1234/2007 establishing a common organisation of agricultural markets as regards the marketing standards for poultrymeat. Disponível em: $<$ https:// eur-lex.europa.eu/legal-content/EN/TXT/?uri=CELEX\%3A32009R1047>. Acesso em abril de 2021.

FONTAGNÉ, L.; von KIRCHBACH, F.; MIMOUNI, M. An assessment of environmentally related nontariff measures, World Economy, Ed. John Wiley and Sons. Hoboken, NJ, v. 28, n. 10, p. 1417-1439, 2005

FRAHAN, B.H.; VANCAUTEREN, M.. Harmonisation of food regulations and trade in the Single Market: evidence from disaggregated data. European Review of Agricultural Economics, v. 33, n. 3, p. 337-360, 2006.

GUIMARÃES, M.H. "Non-tariff Measures in the European Union: Evidence from the Agri-food Sector”. Agricultural Economics Review, vol. 13, no 2, pp. 21-34. 2012.

HENSON, S. J.; LUX, N.; TRAILL, B. Final Report. Partner 4. FAIR97-CT34-81 program, EU Commission, Agricultural Directorate, Bruxelles (unpublished), 2001.

HENSON, S., LOADER, R., SWINBANK, A., BREDAHL, M., \& LUX, N. Impact of sanitary and phytosanitary measures on developing countries (No. Folleto 434.). University of Reading, Department of Agricultural \& Food Economics. 2000.

HENSON, S.; JAFFEE, S. Understanding developing country strategic responses to the enhancement of food safety standards. World Economy, v. 31, n. 4, p. 548-568, 2008.

MARIANO, K. L. P.; LUCIANO, B. T.; SANTOS, L. B. Parlamentos regionais nas negociações comerciais: o Parlamento Europeu e o do Mercosul no acordo União Europeia-Mercosul. Opinião Pública, v. 25, n. 2, p. 377-400, 2019.

MENDONÇA, T.G.; DE CARVALHO, D.E.; REIS, M.P.O. Exportações brasileiras de carne suína Medidas técnicas, sanitárias e fitossanitárias. Revista de Política Agrícola, v. 26, n. 3, p. 124-141, 2017.

MOENIUS, J. Information versus product adaptation: the role of standards in trade. Kellogg School of Management, Northwestern University, 2004 (Working Paper).

MURINA, M.; NICITA, A. Trading with Conditions: The Effect of Sanitary and Phytosanitary Measures on the Agricultural Exports from Low-income Countries. The World Economy, v. 40, n. 1, p. 168-181, 2017.

MURPHY, Kevin M.; SHLEIFER, Andrei. Quality and trade. Journal of development economics, v. 53, n. 1, p. 1-15, 1997.

OLIVEIRA, L. A. A Importância das normas internacionais para o comércio da fruticultura brasileira. 2005. 169 f. Dissertação (Mestrado em Economia) - Universidade de São Paulo, Piracicaba, 2005. 
OTSUKI, T., WILSON J., SEWADEH M. "Saving Two in a Billion: Quantifying the Trade Effect of European Food Safety Standards on African Exports." Food Policy, 26, 495-514. 2001.

PIANI, G.; KUME, H. Fluxos bilaterais de comércio e blocos regionais: uma aplicação do modelo gravitacional. Instituto de Pesquisa Econômica Aplicada (Ipea). Texto para Discussão (TD) 749. Rio de Janeiro, julho de 2000.

SILVA-RÊGO, B. F.; FIGUEIRA, A. R. "The economic face of international co-operative arrangements: the cases of IBSA and CPLP”. Contexto Internacional, vol. 40, nº 1, 2018.

SWINNEN, J. "Economics and politics of food standards, trade, and development." Agricultural Economics 47, no. S1 (2016): 7-19.

VAILLANT M.; VAILLANT P. European Union-Mercosur Negotiations: A Return to Uncertainties. Latin American Business Review, v. 15, n. 3-4, p. 337-362, 2014.

WORLD TRADE ORGANIZATION (WTO). Database. Disponível em: < http://spsims.wto. org/en/Notifications/Search $>$. Acesso em outubro/2019. 